\title{
Effects of food components and the ratio of epitestosterone to testosterone on steroid glucuronidation.
}

-Endogenous testosterone has been known to be used by athletes as a method of enhancing performance in sporting competition.

-The use of testosterone in sport is currently banned and listed on the WADA prohibited substances list.

-UGT2B17 is the most effective UGT enzyme in the glucuronidation of testosterone to testosterone glucuronide (TG), for excretion in urine.

-The excreted TG serves as a marker for testosterone abuse in sport, by measuring the ratio of TG over epitestosterone glucuronide.

-Previous studies have shown pharmaceuticals such as ibuprofen and diclofenac are competitive inhibitors of UGT2B17, however little is known about the effect common foods could have on the metabolism of testosterone.

-The aim of the project was to screen common dietary substances for inhibition of UGT2B17 mediated testosterone glucuronidation as well as determining the interaction of epitestosterone on testosterone glucuronidation at $\mathrm{ng} / \mathrm{ml}$ levels and in gender-different microsomes.

Enzyme assays where performed with $0.1-0.2 \mathrm{mg} / \mathrm{ml}$ enzyme protein, with an enzyme substrate-only preparation as controls, to compare the effects of dietary components TG formation. Reactions where run for 30-90 minutes with a range of initial testosterone concentrations for analysis. The tea samples where dissolved in boiling water with equal weight/volume and wine samples were diluted in $\mathrm{H}_{2} \mathrm{O}$.

An HPLC method was developed to analyse the remaining testosterone to monitor UGT activity. The HPLC method was: methanol/water (80/20) with testosterone dissolved in DMSO, acetonitrile/water (39/61) when testosterone was dissolved in acetonitrile. Measurement was at $246 \mathrm{~nm}$. A reported HPLC method was also used to analyse the key compounds in the tea samples. HPLC method - methanol/water/orthophosphoric acid (20/79.9/0.1). The flow rate for all HPLC analyses was $1 \mathrm{ml} / \mathrm{min}$. LC-MS/MS analysis was used for detection of testosterone at $\mathrm{ng} / \mathrm{mL}$ level for analysis of epitestosterone interaction.

\section{RESULTS - Green and white teas and catechins}

\begin{tabular}{|c|c|}
\hline Samples & $\begin{array}{c}\text { Testosterone glucuronidation } \\
\text { Rate (ng/ml/min/mg prot.) }\end{array}$ \\
\hline Control (enzyme substrate) & $\mathbf{6 8 2 . 0 9} \pm 30.73$ \\
\hline Green tea & $179.56 \pm 22.64$ \\
\hline White tea beard & $\mathbf{2 4 9 . 8 3 \pm 1 8 . 8 7}$ \\
\hline White tea Leaf & $\mathbf{2 4 6 . 2 2} \pm 16.61$ \\
\hline White tea powder & $\mathbf{6 9 . 5 7} \pm 11.04$ \\
\hline Cacao beans & $666.22 \pm 23.55$ \\
\hline Cacao block & $572.89 \pm 20.14$ \\
\hline
\end{tabular}
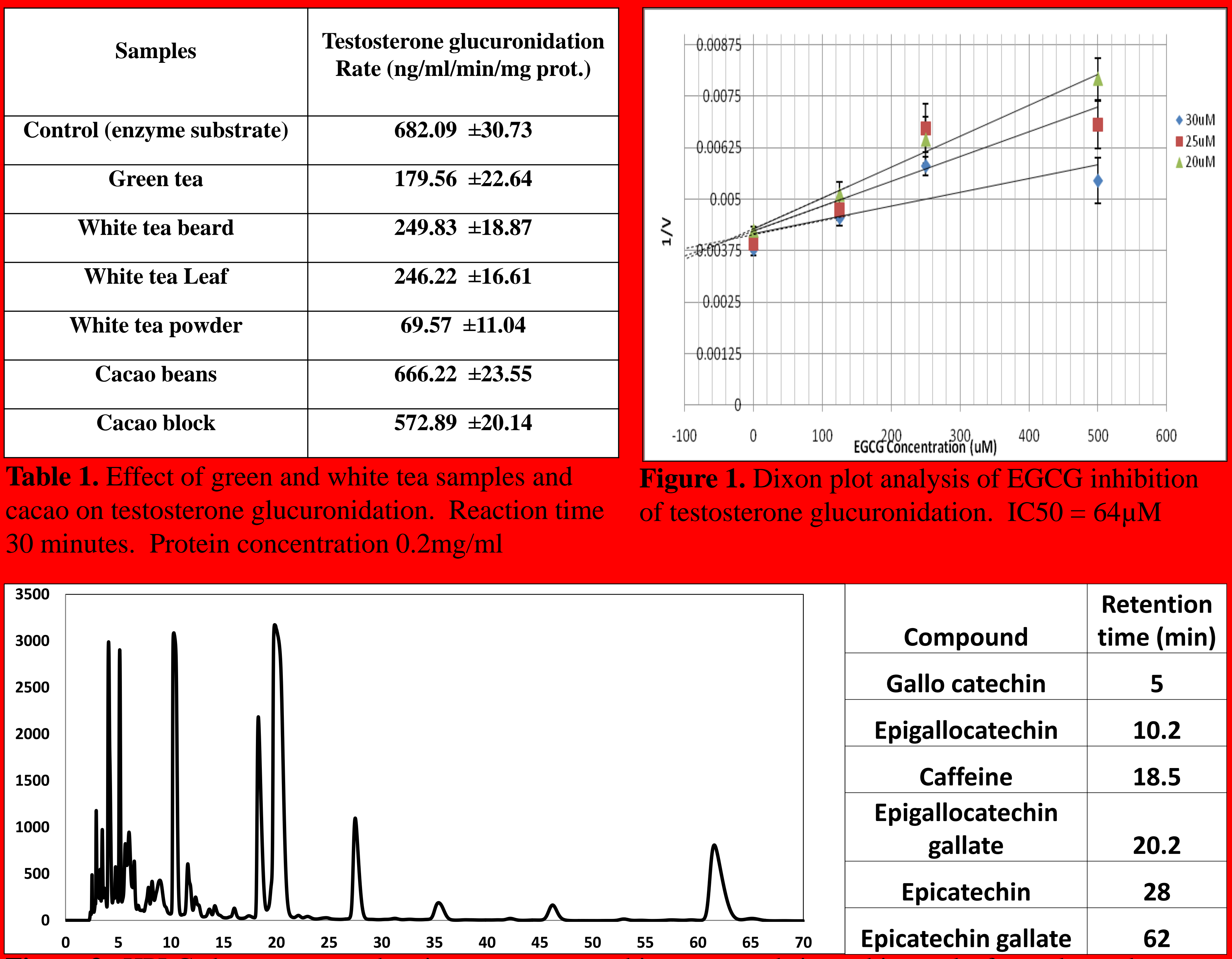

\begin{tabular}{|c|c|c|}
$\begin{array}{c}\text { Epitestosterone } \\
(\mathbf{n g} / \mathbf{m l})\end{array}$ & $\begin{array}{c}\text { T/E } \\
\text { ratio }\end{array}$ & $\begin{array}{c}\text { Testosterone } \\
\text { glucuronidation rate } \\
\text { (ng/ml/min/mg prot. })\end{array}$ \\
\hline $\mathbf{0}$ & & $\mathbf{8 . 2 7} \pm \mathbf{0 . 1 2 9}$ \\
\hline $\mathbf{3 . 1 2 5}$ & $\mathbf{1 6}$ & $\mathbf{8 . 3 0} \pm \mathbf{0 . 0 9 9}$ \\
\hline $\mathbf{6 . 2 5}$ & $\mathbf{8}$ & $\mathbf{8 . 2 8} \pm \mathbf{0 . 0 5 7}$ \\
\hline $\mathbf{1 2 . 5}$ & $\mathbf{4}$ & $\mathbf{8 . 1 6} \pm \mathbf{0 . 1 4 9}$ \\
\hline $\mathbf{2 5}$ & $\mathbf{2}$ & $\mathbf{7 . 9 7} \pm \mathbf{0 . 2 4 0}$ \\
\hline 50 & 1 & $\mathbf{7 . 8 5} \pm \mathbf{0 . 0 6 4}$ \\
\hline 100 & $\mathbf{0 . 5}$ & $\mathbf{7 . 6 4} \pm \mathbf{0 . 0 8 5}$ \\
\hline 200 & $\mathbf{0 . 2 5}$ & $\mathbf{7 . 6 3} \pm \mathbf{0 . 0 8 4}$ \\
\hline
\end{tabular}

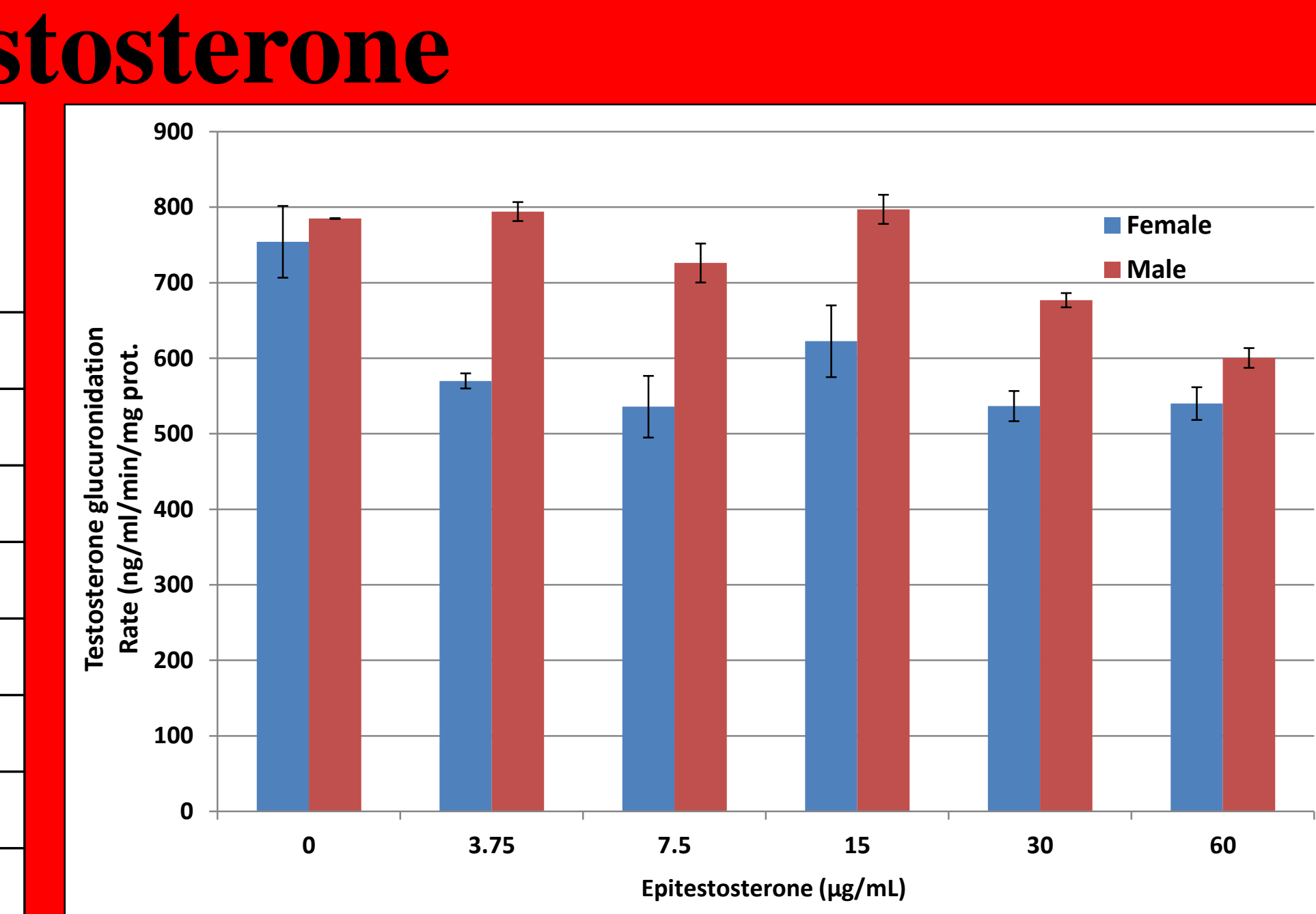

Conclusions

-Commonly consumed dietary teas and red wine interact with testosterone glucuronidation by inhibition of UGT2B17. Epitestosterone reduces the rate of testosterone glucurondation.

-These dietary compounds could have implications on the current method of detecting testosterone abuse in sport by having an impact on altering steroid metabolites in urine as well as potentially altering circulating levels.

-Current studies are analysing further dietary samples for inhibition of these UGT enzymes and analysing these samples at lower serum concentrations.

-References
$1 . \quad$ Sten T et al. (2009). Steroids. 74: 971-977.

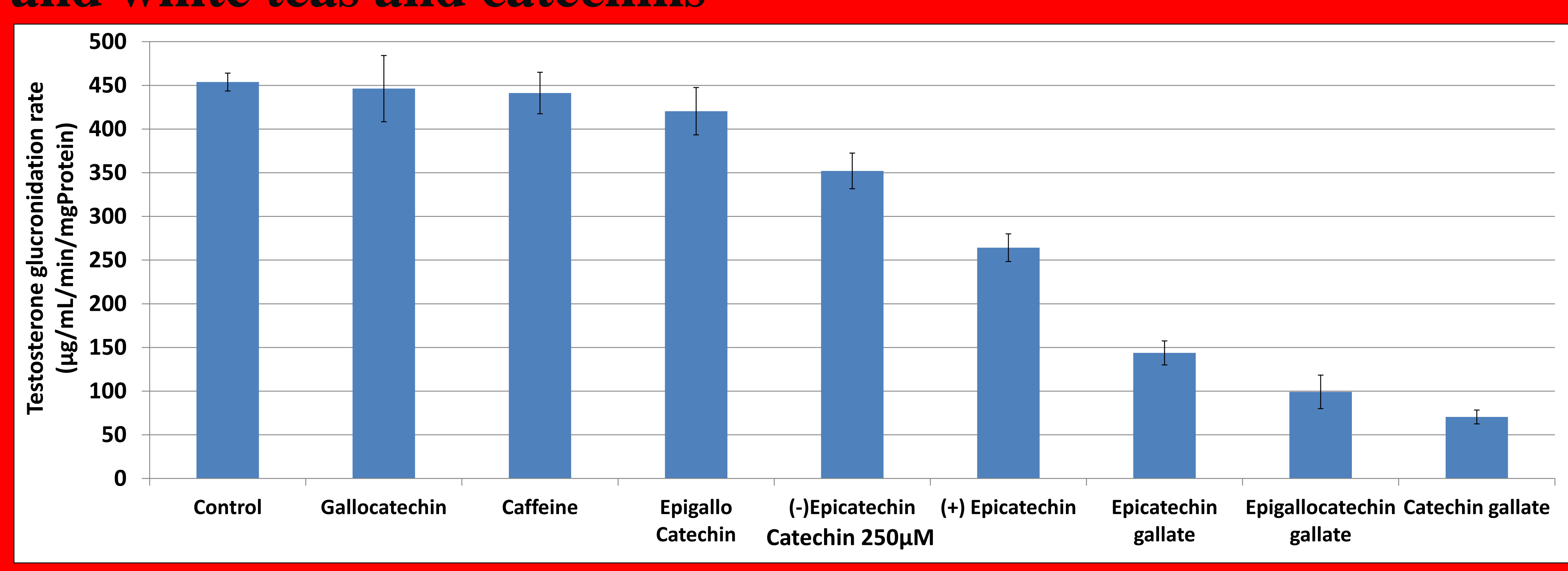

Red wine and phenolic compounds

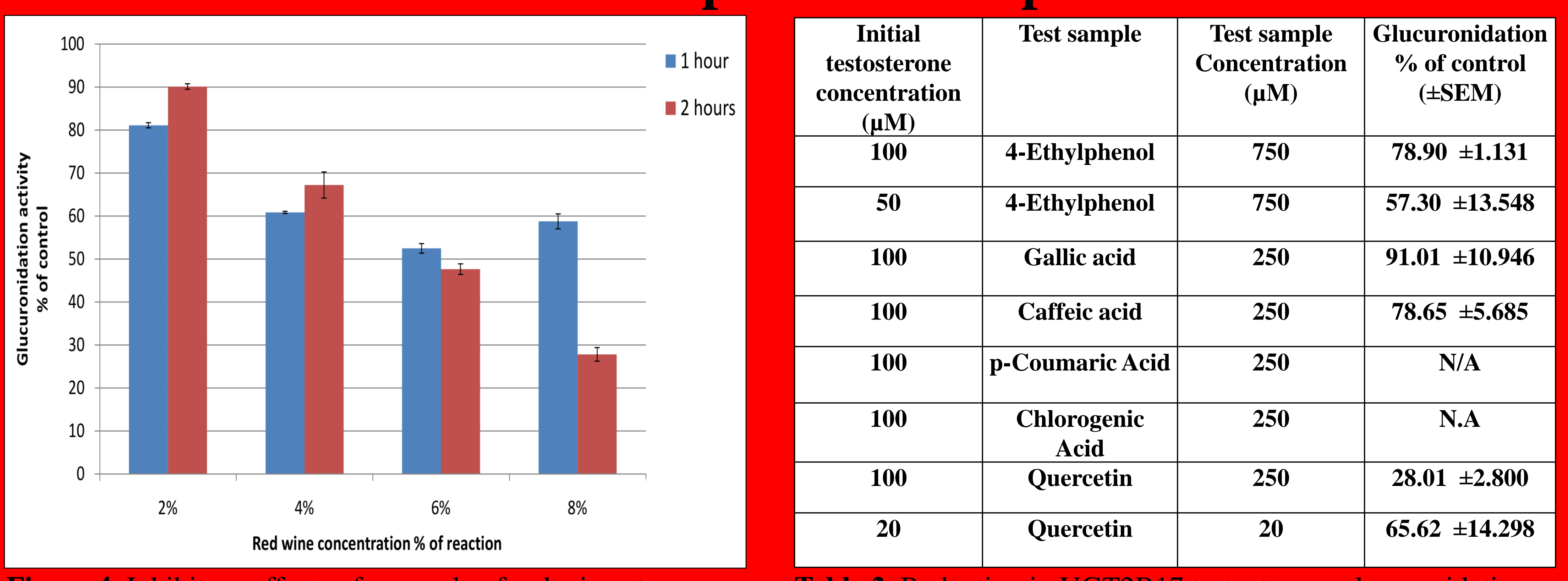

Results and discussion

-The green tea samples caused a reduction in UGT2B17 testosterone glucuronidation activity over a 90 minute period, along with two catechin compounds commonly found in teas and other foods, epicatechin (EC) and epigallocatechin gallate (EGCG).

-The analysis of the tea samples by HPLC revealed the overall concentrations of catechins present in these samples, this appeared to show a correlation of increasing catechin concentration with increased inhibitory effect, this was particularly evident for the powdered white tea sample.

-Inhibition by the catechin compounds appeared greatest at lower initial concentrations of testosterone $(7.5-40 \mu \mathrm{M})$. The EGCG compound also showed competitive inhibition based on the intersecting trendline of the Dixon plot being above the $\mathrm{X}$ axis.

- Studies confirmed the interaction of epitestosterone on testosterone glucuronidation at lower $\mathrm{ng} / \mathrm{ml}$ concentration, representing concentrations commonly found in the body. 